\title{
The Effect of Health Quotient Management within the Interaction Model of Client Health Behavior on Maternal Health Outcome
}

\author{
Wang Zhen-zhen ${ }^{1,2}$ \\ College of Health Science \& Nursing, Wuhan Polytechnic \\ University \\ Wuhan, China \\ 2. Dept. of Nursing, Henan People's Hospital \\ Zhenzhou, China \\ 1099331273@qq.com
}

\author{
Nie Rong ${ }^{1, *}$ \\ 1. College of Health Science \& Nursing, Wuhan \\ Polytechnic University \\ Wuhan, China \\ nie-rong@163.com \\ *Corresponding author
}

\begin{abstract}
This study explored the effect of Health Quotient (HQ) management on maternal quality of life and the incidence of health problem during puerperium in Cox's Interaction Model of Client Health Behavior (IMCHB). A quasi-experimental posttest design with two groups was used. Totally 60 new mothers were conveniently selected and divided into observation group $(n=30)$ and control group $(n=30)$. According to one's HQ level, the observation group was provided with individualized reaching under the guidance of IMCHB, while the control group was provided with conventional teaching. At 42-days postpartum clinic, the incidence of maternal health problem and the quality of life were compared between the two groups. After intervention, the incidences of low back pain, constipation and other health problems in the observation group were significantly lower than those in the control group $(P<0.05)$, and the scores of all dimensions of quality of life in the observation group were significantly higher than those in the control group $(\mathrm{P}<0.05)$. The results indicate that, compared with conventional teaching method, the teaching mode of HQ management based on IMCHB can effectively reduce the incidence of postpartum health problems and improve maternal quality of life.
\end{abstract}

Keywords-IMCHB; Heath quotient; Quality of life; Health education; Puerperium

\section{INTRODUCTION}

Following pregnancy and child-birth, a woman often undergoes marked physical and psychosocial changes. During puerperium period, women are vulnerable to health problems directly related to childbirth and to decreased self-care. Suboptimal maternal physical and mental health problems are often associated with this situation, which are in turn often associated with poor health outcomes both for women and the whole family [1]. Therefore, it is important to optimize women's health in the 6- to 8-week time period after delivery. Cox's interaction model of client health behaviors (IMCHB), a middle range theory, proposes that as healthcare providers tailor interventions and interactions to the uniqueness of the patient, the potential for a positive health outcome increases [2] Previous studies showed that IMCHB has been used as a framework for health providers to implement effective health interventions, predict and assess their effects on patients' health outcomes [2-3]. A health quotient (HQ) is a measure used to assess an individual's overall health and awareness of health issues. Health care providers are increasingly turning to consider it as a shift in the healthcare delivery, optimizing the practice of healthcare [4]. Studies had demonstrated the positive effects of HQ management among patients with gout, ladder Neoplasms after urologic surgery, coronary heart disease, and gestational diabetes [5-8]. However, little is known about its effects within the framework of Cox's IMCHB on maternal health outcome during puerperium period. The purpose of this study was to compare the impact of HQ management within IMCHB and routine health teaching method on maternal quality of life and the incidence of medical complications during postpartum period.

\section{SAMPLE AND METHODS}

\section{A. Sample}

Totally, 60 postpartum patients who agreed to participate were conveniently recruited from the departments of Obstetrics and Gynecology in a local general hospital between December 2016 and March 2017. Inclusion criteria were new mothers aged 20 years or older who delivered a healthy baby at the hospital. They were divided into the observation group $(n=30)$ and control group $(n=30)$ according to their wards. Informed consent was obtained prior to data collection. Before the intervention, a questionnaire included socio-demographic and clinical characteristics, such as age, education, gestational weeks, and delivery patterns, was used to collect patients' basic information to determine there was no difference between the two groups among these indicators (Table 1). 
TABLE I. BASIC INFORMATION OF ALL PARTICIPANTS

\begin{tabular}{|c|c|c|c|c|}
\hline Variable & Observation $(\mathrm{n}=\mathbf{3 0})$ & Control $(n=30)$ & & $\mathbf{P}$ \\
\hline Age (years) & $28.47 \pm 3.598$ & $27.63 \pm 2.385$ & $-1.057^{\mathrm{a}}$ & 0.295 \\
\hline Gestational weeks & $39.37 \pm 1.377$ & $39.10 \pm 1.296$ & $-0.709^{\mathrm{a}}$ & 0.478 \\
\hline Education (n, \%) & & & & \\
\hline Primary school & $1(3.3)$ & $1(3.3)$ & \multirow{3}{*}{$2.479^{\mathrm{b}}$} & \multirow{3}{*}{0.290} \\
\hline Secondary school & $4(13.3)$ & $9(21.7)$ & & \\
\hline Higher educated & $25(83.3)$ & $20(75.0)$ & & \\
\hline \multicolumn{5}{|l|}{ Delivery pattern } \\
\hline Spontaneous labor & 11(36.7) & $14(46.7)$ & \multirow{3}{*}{$1.780^{\mathrm{b}}$} & \multirow{3}{*}{0.411} \\
\hline cesarean & $14(46.7)$ & $9(30.0)$ & & \\
\hline Vagina assistant & $5(16.7)$ & $7(23.3)$ & & \\
\hline
\end{tabular}

\section{B. Methods}

In the control group, one day before their discharge, all new mothers received routine bedside education currently used in the hospital. They were verbally informed necessary information on the maternal education sheet for mothers and her baby. On the day of discharge, each mother received a New Mother Handbook containing information on self-care and infant care, the schedules and locations of baby immunization, the time of clinic visit. After one week and two weeks, nurses made follow-up calls asking the mother if she had any questions about her own or her baby's care.

In the observation group, one day before their discharge, each new mother was assessed her HQ level and asked her learning need according to Postpartum Women Health Quotient Scale (PWHQS) containing information and skills on health consciousness, maternal health knowledge, infant health knowledge, maternal health care ability, and infant health care ability [9]. Two experienced nurses were to prepare pictures, videos, and written information, and demonstrate the skills on each new mother's wishing list. Each mother was to practice her chosen skills and back-demonstrate them to make sure she could perform well. During this period, nurses were to inform, clarify and help to build up their self-confidence. On the day of discharge, each mother received a New Mother Handbook developed on PWHQS and asked to join a WeChat group created by the investigator. There were 3 administrators including one experienced nurse, one primary care physician, and one nursing master student in the WeChat group. Three modules were created and notifications on self-care and infant care were pushed weekly. In this WeChat group, new mothers shared their experience and asked questions on self-care and infant care.

After 5 weeks of discharge, a nurse was to call all participants in two groups to make an appointment about their 42-day postpartum clinic visit and whether she agreed to continue to participate. All the participant made agreement and were at clinic on schedule. They completed the brief questionnaire of WHO quality of life (WHO-QoL) [10] and a survey on whether they experienced any medical complications during postpartum period, such as low back pain, joint pain, hemorrhoids, constipation, mastitis, breast soreness, cracked nipple, wound infection, postpartum hemorrhage, gingival bleeding, and oral ulcers. SPSS 20.0 was used for data analysis.

\section{RESUlTS}

\section{A. The Incidences of Medical Complications}

After intervention, there were significant difference in medical complications between the control and observation groups, except of oral ulcers $(\mathrm{P}<0.05)$ (Table 1$)$.

TABLE II. THE INCIDENCES OF MEDICAL COMPLICATIONS BETWEEN TWO GROUPS

\begin{tabular}{|c|c|c|c|c|c|c|}
\hline \multirow{2}{*}{ Variables } & \multicolumn{2}{|c|}{ Observation $(n=30)$} & \multicolumn{2}{|c|}{ Control $(\mathrm{n}=30)$} & \multirow{2}{*}{$\chi^{2}$} & \multirow{2}{*}{$\mathbf{P}$} \\
\hline & yes & no & yes & no & & \\
\hline low back pain & $15(50.0)$ & $15(50.0)$ & $24(80.0)$ & $6(20.0)$ & 5.934 & 0.015 \\
\hline joint pain & $9(30.0)$ & $21(70.0)$ & $12(40.0)$ & $18(60.0)$ & 0.659 & 0.417 \\
\hline hemorrhoids & $13(43.3)$ & $17(56.7)$ & $15(50.0)$ & $15(50.0)$ & 0.268 & 0.605 \\
\hline constipation & $10(33.3)$ & $20(66.7)$ & $19(63.3)$ & $11(36.7)$ & 5.406 & 0.020 \\
\hline mastitis & $1(3.3)$ & $29(96.7)$ & $4(13.3)$ & $26(86.7)$ & 1.964 & 0.350 \\
\hline breast soreness & $7(23.3)$ & $23(76.7)$ & $12(40.0)$ & $18(60.0)$ & 1.926 & 0.165 \\
\hline cracked nipple & $7(23.3)$ & $23(76.7)$ & $13(43.3)$ & $17(56.7)$ & 2.700 & 0.100 \\
\hline wound infection & $1(3.3)$ & $29(96.7)$ & $2(6.7)$ & $28(93.3)$ & 0.351 & 1.000 \\
\hline postpartum hemorrhage & $0(0)$ & $30(1.0)$ & $1(3.3)$ & $29(96.7)$ & 1.017 & 1.000 \\
\hline gingival bleeding & $5(16.7)$ & $25(83.3)$ & $8(26.7)$ & $22(73.3)$ & 0.884 & 0.347 \\
\hline oral ulcers & $2(6.7)$ & $28(93.3)$ & $2(6.7)$ & $28(93.3)$ & 0.000 & 1.000 \\
\hline
\end{tabular}




\section{B. Equations}

After intervention, the total score of WHO-QoL and scores of each dimension in the observation group were significant higher than those in the control group $(\mathrm{P}<0.01)$ (Table 3).

TABLE III. SCORES ON QUALITY OF LIFE BASED ON WHO-QOL

\begin{tabular}{|l|l|l|l|l|}
\hline \multicolumn{1}{|c|}{ Variables } & Control $(\mathbf{n}=\mathbf{3 0})$ & Observation $(\mathbf{n}=\mathbf{3 0})$ & T & P \\
\hline Physical & $41.67 \pm 13.67$ & $63.33 \pm 12.69$ & -6.364 & $<0.001$ \\
\hline Psychological & $48.33 \pm 16.14$ & $70.83 \pm 17.81$ & -5.127 & $<0.001$ \\
\hline Social & $49.58 \pm 18.99$ & $74.58 \pm 18.99$ & -5.097 & $<0.001$ \\
\hline Environmental & $40.73 \pm 14.94$ & $65.73 \pm 14.94$ & -6.480 & $<0.001$ \\
\hline Total QoL & $2.50 \pm 0.900$ & $3.50 \pm 0.900$ & -4.302 & $<0.001$ \\
\hline Health status & $2.53 \pm 0.860$ & $3.53 \pm 0.860$ & -4.502 & $<0.001$ \\
\hline
\end{tabular}

\section{Discussion}

This study has shown that using HQ management within the IMCHB can significantly decrease the incidences of medical complications during puerperal period and increase new mothers' quality of life than using routine bedside discharge teaching method.

Experiencing the birth of a baby is generally happy but somewhat anxious for a new mother. Previous studies have shown that lack of knowledge on how to take care of themselves and the infant often made new mothers be vulnerable to any maternal physical and mental health problem $[1,12,13]$. In this study, the results of lower overall incidence of medical complications, except for oral ulcers, during puerperal period in the observation group is consistent with Hong's study [14]. It is possible that using health quotient management within the IMCHB may has more positive effects on helping new mothers how to adjust their body position appropriately when breastfeeding the infant, and to healthy eat. Moreover, the lower incidences of cracked nipple $(23.3 \%$ vs. $43.3 \%)$, breast soreness ( $23.3 \%$ vs. $40.0 \%)$, and mastitis $(2.3 \%$ vs. $13.3 \%$ ) in the observation group were also found, which is consistent with Zhang's study [15]. It shows that using health quotient management within the IMCHB may better help new mothers know well about breast care and how to breastfeed the newborn and infant correctly and successfully.

This study also found that, compared to those in the control group, the overall score of QoL and the scores of each dimension of QoL were much higher in the observation group. It shows that using HQ management within the IMCHB has more positive effects on new mothers' well-being.

It has been reported that Chinese women generally have a lack of knowledge and health behaviors on postpartum health $[1,10]$. In addition, Chinese 'sitting in month' culture, to some extent, confines postpartum women's health consciousness and self-care practices. Suboptimal physical and mental health conditions will in turn occur. In this study, the contents of interventions were developed according to components of PWHQS, including health consciousness, health knowledge, and perceived health ability [10]. It may help improve postpartum women's physical and mental conditions, knowledge about health, and self-management ability related to physical, psychological, and social adaptive well-being $[5,10]$.
Moreover, the procedure of HQ management was designed on the base of Cox's IMCHB. It emphasizes a patient-centered holistic model of care and uniqueness of the patient and provides a method to document the outcomes based on individualized holistic care [11]. In the observation group, each new mother was assessed by HQ and individualized education was delivered based on one's own information, knowledge, and skill needs. Moreover, the extended HQ management process was conducted by using WeChat group, which emphasized the interaction between nurses and new mothers from hospital settings to home-based settings. In contrast, in the control group, routine teaching method and follow-up may be not sufficient in identifying and meeting unique postpartum health care needs. It is also possible that there was a lack of interaction between healthcare providers and postpartum women in a short hospital stay.

There were some limitations in the study. First, selfselected convenience sample from one hospital setting and small sample size limit of this study its generalization to a wide population. Second, Hawthorne effect may exist because either participants or nurses were not blinded.

\section{V.CONCLUSION}

The results of this study demonstrate the positive value of HQ management within Cox's IMCHB for new mothers during postpartum period. Nurses can use this information to design and implement postpartum discharge teaching based on individual patient choice and needs in order to improve postpartum women's general well-being and quality of nursing care. Further research needs a stricter design and extend to a larger sample size to test its effects in other settings.

\section{REFERENCES}

[1] L.M. Mao, X.F. Sun, X.P. Zhang, N.H. Yang, L.P. Hao, and X.F. Yang. "A survey study on nutrition knowledge and diet behavior among parturient women in Hubei Province," . J Hyg Res, vol.34, pp.118-120, 2005.

[2] Cox CL. "An interaction model of client health behavior: theoretical prescription for nursing ," Adv Nurs Sci, vol. 5, pp. 41-56, 1982.

[3] Bai YT, Han L. "Research progress on Cox health behavior interactive mode," Chin Nurs Res, vol. 30, pp. 1158-1161, 2016. 
[4] Guo J, Dixon JK, Whittemore R, etc. "Psychometric testing of the Health Quotient questionnaire: a measure of self-reported holistic health ,"J Adv Nur, vol.66, pp.653-663, 2010.

[5] Lu AL, Peng XW. "Application of health quotient management in health education among patients with gouty," Med Forum, vol. 20, pp. 283284, 2016.

[6] Wang J, Wang R. "The application of health quotient in the nutrition support among elderly patients with ladder Neoplasms after urologic Surgical Procedures ," Chin J Nurs, vol. 48, pp. 1023-1024, 2013.

[7] Wang Y, Zhou DQ, Yao HH. "The application of health quotient assessment in health management among elderly patients with coronary heart disease ," Chin J Mod Nurs, vol. 20, pp. 3728-3730, 2014.

[8] $\mathrm{Lu} \mathrm{Y,} \mathrm{Cao} \mathrm{SH,} \mathrm{Zhang} \mathrm{J.} \mathrm{“} \mathrm{Influence} \mathrm{of} \mathrm{health} \mathrm{quotient} \mathrm{training} \mathrm{on} \mathrm{the}$ treatment compliance of outpatients with GDM " Chin Prim Health Care, vol. 26, pp. 46-48, 2012.

[9] Wan, S.X., Wang, W., Li, C.H., etc. "Development and statistical test of Health Quotient Assessment Scale for puerperia,” Nurs J Chin People's Liberation Army, vol. 32, pp. 27-31, 2015

[10] Fang JQ, He YT, Li CX. "Reliability and validity for Chinese version of WHO quality of life scale ," Chin Ment Health J, vol. (4), pp. 203-205, 1999.

[11] Wagner DL; Bear M; Davidson NS. "Measuring patient satisfaction with postpartum teaching methods used by nurses within the interaction model of client health behavior," Res Theor Nurs Pract, vol. 25, pp. 176-90, 2011.

[12] Song RH, Zhang JM. "Effect of psychological intervention within Freud's Personality Theory on compliance behavior and quality of life among parturient women with depression," Med J Chin People's Health, vol. 29, pp. 104-106, 2017.

[13] Yang AJ. "Clinic value of postpartum mammary nursing on Mammitis Prevention in parturient women," Higher MED EDUC, China, vol. 12, pp. 145-146, 2017.

[14] Hong M, Wu B, Zhu SZ, etc. "Effect of postpartum rehabilitation education on maternal health," Matern Child Health, China, vol. 29, pp. 4716-4718, 2014.

[15] Zhang WY. "Effect of health education on the coping styles and the hope level among postpartum women," Chinese J. Health Educ, vol. 32, pp. $458-461,2016$. 